\title{
Research Progress on Repair and Reinforcement of Beams in Timber Building
}

\author{
Xiaofeng Zhang, Youfu Sun*, Mingbin Liu and Ruyuan Yang \\ Department of Wooden Structure Construction, Nanjing Forestry University, Nanjing 210037, China
}

\begin{abstract}
Timber building has been widely used for its renewable, excellent structural performance and aesthetic value. The "beam" is one of the most important components in the upper structure of a timber structure; beam as the main force component is under long-term loading may cause it to crack and resulting in a reduced safety factor. In this paper, the predecessors' research results are analyzed and summarized from the perspectives of the damage reinforcement methods of timber beams in ancient building and modern building, as well as the research hot-pots of modern timber beams, in order to lay the foundation for subsequent related research..
\end{abstract}

\section{Introduction}

The timber structure has a long history and it is one of the earliest forms of architectural structure adopted by mankind. The "beam" in the timber structure is one of the most important components in the upper frame. The weight of the components and the roof in the upper frame of the building plays an important role in building safety. Ancient construction is an important historical and cultural heritage of China, and its production, development and change run through the whole process of the history of ancient building. The timber structure is also the main representative of the achievements of ancient Chinese building. However, due to the long-term effects of changes in temperature and humidity of the environment and the defects of the timber itself, cracking occurs in the timber components, which reduces the bearing capacity of the components and thus affects the safety of the entire structure. Therefore, it is of great significance to reinforce these components [1].

Since timber is an anisotropic natural material, its shear strength and transverse tensile strength are low [2], and the timber beams in ancient buildings have longterm effects on loads, and the timber beams produce cracks along the longitudinal direction. The timber beams in ancient buildings are subjected to long-term loading, and longitudinal cracks are generated in the timber beams. The predecessors studied the possible damage forms of timber beams in ancient buildings and discussed the methods of timber beam reinforcement.

This paper mainly analyzes and summarizes the research results of the predecessors' research on the destruction methods and reinforcement methods of the timber beams of ancient buildings and modern buildings.

\section{The failure mode and reinforcement method of timber beams in ancient construction}

\subsection{Main failure mode of timber beam in ancient construction}

\subsubsection{Decay and destruction}

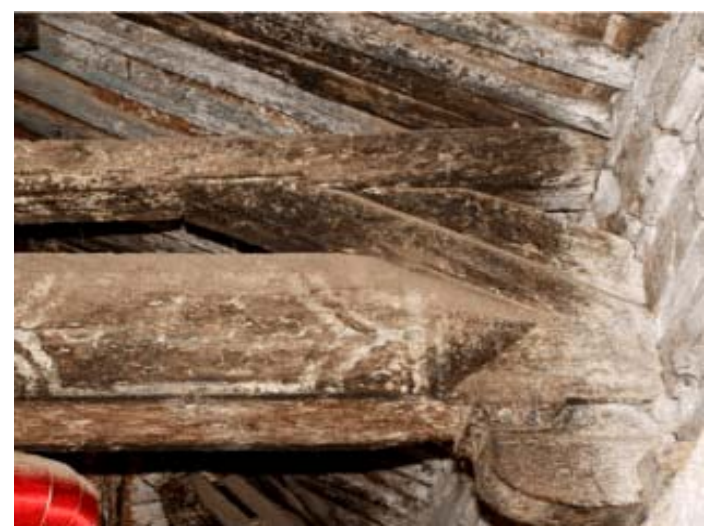

Fig.1 Decadent destruction ${ }^{[1]}$

The timber beams of ancient construction that have been in a humid environment for a long time will cause decay of the components [3]. For example, as shown in Fig.1 the corner beam of the roof, because the position of the corner beam is on the roof, when the roof leaks, it will cause decay and damage to the timber beam due to the accumulation of water. Corrosion causes the cross-

*Corresponding author: yfsun@njfu.edu.cn 
sectional area of the beam members to be reduced in tension, compression, bending, shearing, etc., resulting in a decrease in the bearing capacity, which is very unfavourable to the entire timber structure.

\subsubsection{Cracking damage}

There are mainly two kinds of cracks in the timber beam. First, due to the tensile strength of the transverse stripes of the timber and the low shear strength of the grain, the longitudinal cracks along the longitudinal direction of the timber beam as shown in Fig.2 are generally larger in size; second, due to the large moisture content of the components at the time of production, and due to the change of moisture content in the environment, the moisture in the timber beams will balance with the moisture content in the environment. In this process, the surface of the timber beams will produce shrinkage cracks.

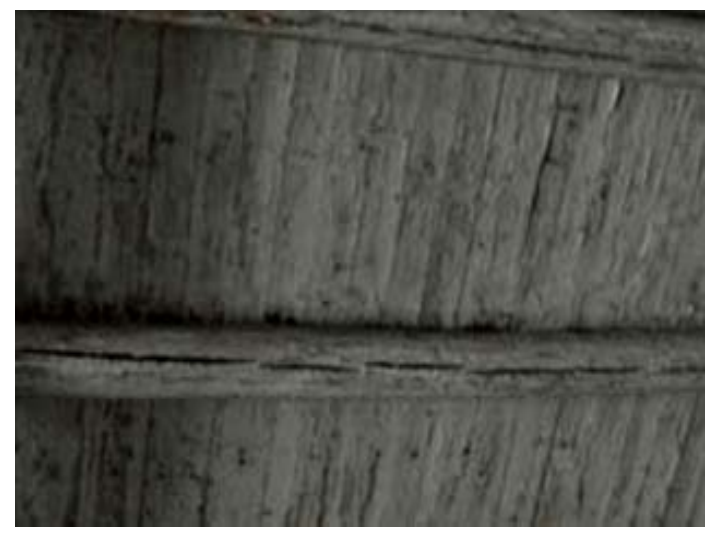

Fig.2 Cracking destruction ${ }^{[1]}$

\subsubsection{Dust damage}

Most of the timber beams and columns of ancient buildings are connected by mortise-tenon. The main advantage is that the seismic effect is quite good. Under the action of earthquakes, mortise and tenon consume energy and reduce damage through frictional slip and extrusion deformation. However, the pulling and squeezing of the mortise-tenon node causes the stiffness of the node itself to decrease, and the structural node transitions from semi-rigid to articulated. The plucking causes the effective cross-sectional area of the beam and column members to be reduced, which is easy to cause tensile, compressive, bending and shearing damage, which has certain influence on the structural integrity.

\subsubsection{Deflection change}

It is mainly embodied in the timber beams of ancient buildings, under the long-term load, the deflection of the mid-span is too large due to the decrease of the mechanical properties of the timber, thus exceeding the allowable range of the specification. Not only affects the appearance of the timber beams, but if the reinforcement measures are not taken in time, the timber beams will be damaged by bending over time.

In addition to the above four major forms of damage, there are some damages due to other factors. For example, when an ancient building is located in a river course, a silty soil layer or a potential landslide zone, the foundation is destroyed due to landslides or uneven settlement of the foundation; when the bottom of the ancient building floats on the top of the column, under the action of earthquake the bottom of the column is prone to lateral displacement; the ancient building beam rests on the top of the column or the top of the bucket, and the skew caused by the lateral movement of the beam with the top of the column under the action of earthquake; and the damage of the ridge pieces and the decoration damage.

\subsection{Repair and reinforcement method of timber beam in ancient construction}

The principle of strengthening timber beams in ancient buildings: the "originality, necessity and reversibility" of historical building protection should be followed and we must maximize the original features of ancient buildings and meet the principle of restoration as the past.

\subsubsection{Repair methods in existing projects}

\section{- Complementing and patching}

The method of complementing is to directly remove the decayed part of the component, and after the anticorrosion treatment, the dry timber is added according to the original size shape, and the method of sticking with the water-resistant adhesive is applied to the horizontal crack depth of the beam is smaller than the beam width or when the diameter is $1 / 4$, stick with timber strips and water-resistant adhesive, and stick the gap tightly as shown in Fig.3 [4].The repair method of the patch and the inlay only has a certain repairing effect on the component, but it is difficult to restore the overall working performance of the timber beam, and it is not an effective repair method.

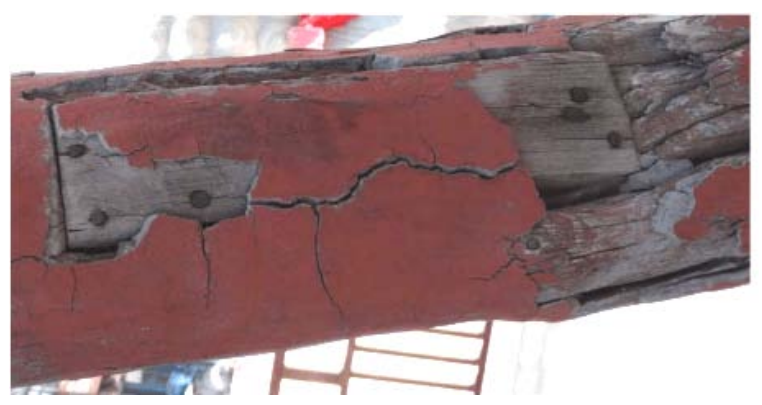

Fig.3 Repair timber beam of ancient buildings by complementing ${ }^{[1]}$

- Strengthening with iron hoop 
The iron beam can be repaired on the surface of the timber beam to repair the timber beam as shown in Fig. 4. The engineering application of the repairing and strengthening method for the damaged member has a long history. In the "Engineering Practice" of the Qing Dynasty, there is an iron hoop to the timber [5]. The method has certain effects on the repair of the timber beam, but the iron piece is easily rusted, and the reinforcing effect after the rust is greatly weakened.

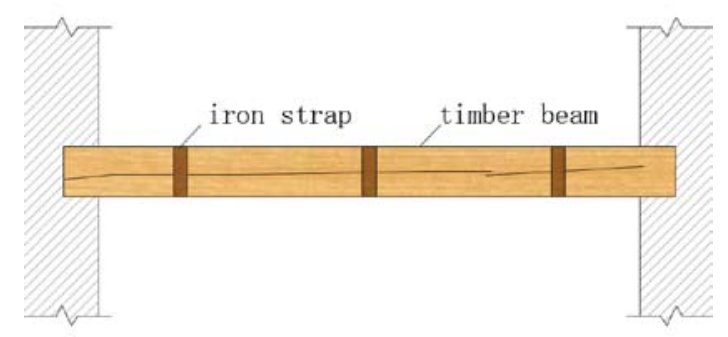

Fig.4 Reinforced timber beam of ancient buildings with iron strap

\section{- Bottom-supported steel rod reinforcement}

There are many forms of reinforced timber beams supported by the bracing steel tie rods. This method as shown in Fig.5 is generally applicable to beams with small cross-sections, insufficient bearing capacity or excessive deflection. Before the reinforcement, it is necessary to check whether the material of the end of the timber beam is decaying or insects, and the fixing of the tie rod can be ensured only under the condition that the material is relatively intact.

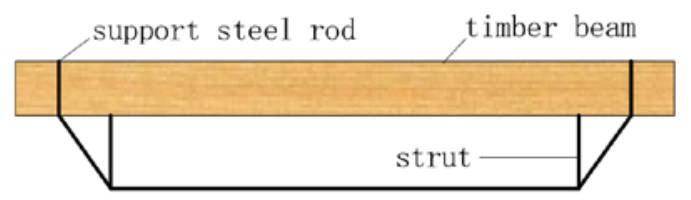

Fig.5 Reinforced timber beam of ancient buildings with bottom-supported steel rod

\section{-Reinforcement by clamping and docking methods}

For the decay of the beam end timber and the insects, the timber beam can be reinforced by the method of clamping or supporting as shown in Fig.6. When the beams of multiple floors are reinforced, the support points should be aligned up and down. After the temporary support is completed, the damaged parts of the timber beams are sawed and reinforced by the clamping and supporting methods. This kind of reinforcement method has a great influence on the appearance of the components, and is not suitable for buildings with strict requirements on appearance.

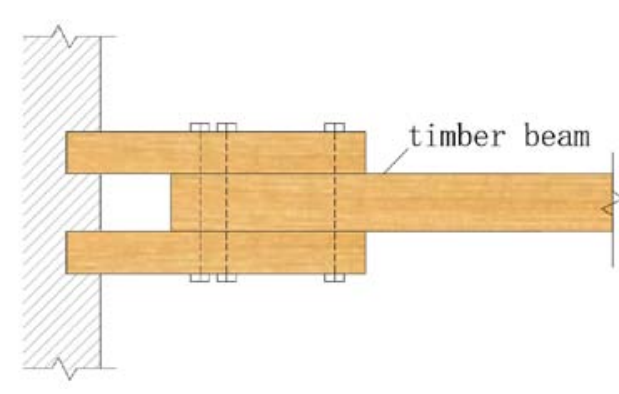

Fig.6 Reinforced timber beam of ancient buildings by clamping or supporting

\section{-Chemical grouting method}

The pressure is injected into the interior of the timber. In addition to repairing the defects of the timber component and increasing its strength, the reinforcing member can also improve the anti-corrosion and insect-proof ability of the strengthened member and increase the dimensional stability. This repair method in the existing engineering cannot substantially enhance the overall working performance of the timber beam, or has durability problems under the long-term effect of the environment, or it is only suitable for the case where the material of the timber itself is better, or has a greater influence on the appearance of the component. These repair methods are both inadequate and limited.

\subsubsection{Modern reinforcement technology}

\section{- FRP reinforced timber beams}

Fiber reinforced plastics (FRP) as shown in Fig.7 is widely used in the reinforcement of timber structures due to its geometric plasticity and light weight. The tensile strength of fiber cloth along its grain direction is high, and the compressive strength of timber is higher. In the FRP-reinforced timber beams, the performance of these two materials can be well utilized, and the materials have good bonding properties, which can work well together.

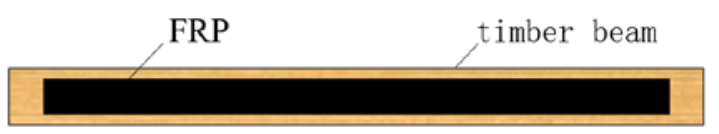

Fig.7 Reinforced timber beam of ancient buildings with FRP

\section{- Nanomaterial reinforcement technology}

In recent years, foreign scholars have also used carbon nanotube-reinforced polymer resins to repair ancient timber structures. This repairing technology can repair 
localized parts of rotten, insect-resistant timber parts or joints. The carbon nanotube resin coating is applied to the surface of the timber component or the partial impregnation of the timber component can improve the bearing capacity and bending strength of the timber [6].

\section{-Self-tapping screws for reinforcing timber beams}

Self-tapping screws are a new type of products that have been developed with the development of modern technology. Due to their self-tapping drill bits, they can be easily penetrated into timber beams without affecting the performance of the timber beams themselves. As shown in fig. 3 , the tensile strength of self-tapping screws is higher, when it penetrates into the timber beam along the vertical timber transverse direction, it can establish a well bond with the timber, then improve the horizontal grain tensile strength and the shear resistance of the timber beam, and enhance the overall working performance of the timber beam, thereby to improve the bearing capacity of the timber beam [7].

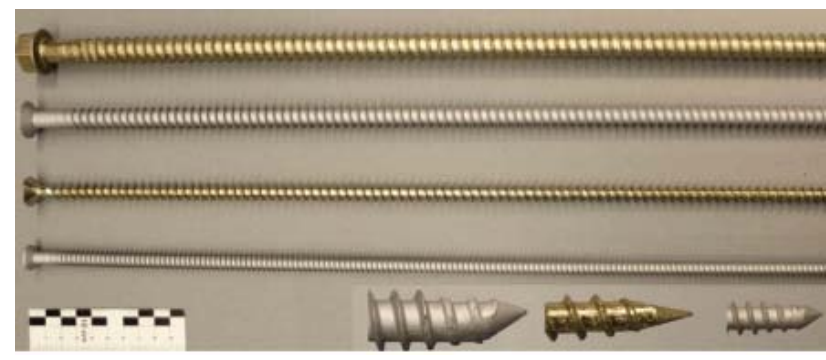

Fig. 3 Self-tapping screws and the bond between self-tapping screws and timber ${ }^{[7]}$

Jonsson's experimental study on self-tapping screws for reinforced timber curved beams found that self-tapping screws can effectively reinforce timber beams. The test found that the failure mode of the unreinforced beam is mainly the brittle transverse grain tensile damage. The force and displacement are linearly related before reaching the ultimate load, the beam with the selftapping screws strengthened after the damage has been compared. The maximum height of the reinforced beam is increased by $20 \%$, the overall working performance of the beam is improved, and the ultimate deformation is greatly improved, which is twice that of the unreinforced beam. For the pre-reinforced beam, the bearing capacity is increased by up to $50 \%$, the ultimate deformation is increased by 1.5 times [8]. Xiaobin $\mathrm{S}$ et al. carried out experimental and theoretical analysis on the flexural capacity of self-tapping screws with longitudinal joints and the self-tapping screws. Based on the beam theory, the authors deduced the factors such as the length of the longitudinal joint and the height of the section and the angle and spacing of the self-tapping screws. Calculation method of bearing capacity repair coefficient. The test results show that the error between the theoretical formula and the test results is $\leqslant 21 \%$, which has high prediction accuracy and can be used to guide engineering practice [9].
The above several reinforcement methods have their own advantages and disadvantages. Self-tapping screws reinforced timber beams as a new method for reinforcing timber beams, its research and application is still in its infancy, because the reinforcement effect is better, the appearance of timber beams is not damaged after reinforcement and the overall mechanical performance is better.

\section{Research Status of Modern Timber Structure Beams}

The mechanical properties of modern timber -glued timber beams, the mechanical properties of composite beams, the reinforcement of defective beams, the beamcolumn joints and the steel-timber combination are the current research hotspots, as shown in Fig. 4.

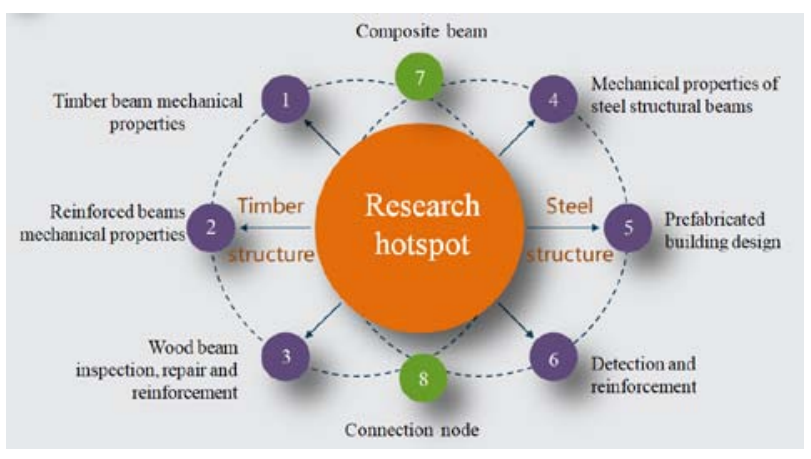

Fig. 4 Hot topics in the field of timber structure and steel structure

\subsection{Mechanical properties of glulam beams}

At present, the research on glulam beams mainly focuses on the research of flexural and shear resistance. In addition, the joints of the beam-column system and the lateral resistance are also the hotspots of current research.

Minjuan $\mathrm{H}$ et al. obtained the failure mode, bending moment-turn curve, hysteresis curve, strength, stiffness, ductility and energy dissipation performance of each group of nodes through the lateral force test of four sets of beam-column joints under monotonous and reciprocating loading. The effects of different bolt rows and self-tapping screws on the lateral force resistance of the joints were studied. The results show that the cracks appear in the common nodes early and develop rapidly. Increasing the number of bolt rows can increase the strength and ductility of the joints, and the strength is more obvious[10]. Lei $\mathrm{C}$ conducted a bending test on four different sizes of glulam beams. The failure modes and failure mechanisms of glulam beams were discussed. The whole process of gluing beams was systematically analyzed, bending strength dimensional effect, ductility, deflection and flexural capacity. The test results show that the flexural strength of the glulam beam gradually decreases with the increase of the size, which has obvious size effect. Based on the Weibull brittle fracture 
theory, a two-parameter Weibull model was established, and the combined size effect coefficient of larch glulam beam length and height was 0.275 [11].

\subsection{Mechanical properties of glulam beams}

The main components of the composite beam are timbertimber combination, steel-timber combination, woodplastic combination, timber and glass combination, etc. The purpose of the combination is to improve the bending mechanical properties. Deliang $\mathrm{X}$, Weiqing L, Huifeng $\mathrm{Y}$ et al. experimentally studied the structural properties of a total of 20 bolted specimens of four different timber thicknesses, and obtained the bearing capacity of the timber-steel filler bolts when they were pulled, and discussed their failure modes. Studies have shown that the failure mode, bearing capacity and ductility of timber -steel bolt connections are related to the relative thickness of the side members in the joint. Timber -steel bolting has wide application prospects in modern timber structures. The research results can provide reference for the processing, design and application of modern timber structures in China [12]. In order to improve the mechanical properties of ordinary glulam beams, a reinforcement method of attaching steel plates or adding screws at the bottom is proposed to form steel plate reinforced glulam beams. The research shows that the bearing capacity of the beam is increased by $73.3 \%, 90.0 \%$ and $71.0 \%$ after the reinforcement of the 2 , 3 and $4 \mathrm{~mm}$ thick steel plates. The bearing capacity increases first and then decreases with the increase of the thickness of the steel plate; after the screws are set, the bearing capacity of the beam is increased by $76.4 \%$, $96.9 \%$ and $148.6 \%$ respectively. As the thickness of the steel plate increases, the bearing capacity increases, and the reinforcing effect of the screw is obvious when the steel plate is thick. After the steel plate is strengthened, the ultimate deformation of the beam is $6.2 \% \sim 61.1 \%$ higher than that of the ordinary glulam beam. The influence of the thickness of the steel plate and whether the screw is set on the deformation capacity of the beam is similar to that of the bearing capacity [13]. Feibin W, Zeli $\mathrm{Q}$ et al. studied the bending resistance of GFRPreinforced reinforced timber beams. The test results show that the grooved gluing beams can significantly reduce the bending resistance of the glulam beams, while the circular notches are for timber. The degree of damage is less than that of the square groove; at the same time, the glulam beam is strengthened in the tension zone and the compression zone; the effect is better than that of the reinforcement in the tension zone alone, and the ultimate load and ductility coefficient are increased by $5.88 \%$ and $16.85 \%$, respectively. When the timber beam tension zone is strengthened, the number of GFRP bars is increased. In addition to the improvement of ductility, the stiffness and ultimate bearing capacity are reduced. When the circular groove is used for reinforcement, the reinforcing effect is better than that of the square groove [14].

\subsection{Study on mechanical properties of timber beam reinforcement}

The research on timber structure reinforcement methods mainly includes carbon fiber cloth (CFRP) reinforcement, glass fiber cloth (GFRP), basalt fiber (BFRP) reinforcement, diagonal bracing method, nailing method, caulking and hoop method [15], self-tapping screws reinforcement method [16] and other methods, the above methods are mostly reinforced with fiber cloth. This paper mainly reviews CFRP reinforced timber beams.

\subsubsection{CFRP material reinforcement ordinary wood beam}

Plevris et al. [17] first carried out a test on the unidirectional CFRP cloth of the tensioned side of the rectangular section of the wooden beam. The test results showed that the flexural strength, stiffness and ductility of the wood members reinforced with the CFRP sheet are strengthened. Zhang Dazhao et al. [18].found that the stiffness and ductility of the strengthened members were improved to some extent by CFRP reinforcement of round wooden beams, and the flexural capacity was improved by $40 \% \sim 50 \%$ Johns et al [19], Gangarao et al [20] and Jianxun $M$ et al [21] also carried out experimental research on the reinforcement of rectangular wooden beams with CFRP cloth. CFRP cloth can compensate for natural defects, prevent local cracking, effectively restrain crack development, and significantly improve The flexural capacity and stiffness of the reinforced wooden beams are greatly improved by $9 \% \sim 100 \%$ and $2.5 \% \sim 9.2 \%$ respectively. Qingfeng X et al. [22] conducted a CFRP-reinforced tensile test of the timber beam in the tensile zone (the presence of obvious knots) for the common knot problem of wood. The knots caused brittle failure. There are no obvious knot members, and the flexural capacity is increased by $53 \% \sim 109 \%$. The test results show that this reinforcement method can appropriately reduce the material grade requirements of the components, thereby improving the utilization rate of wood. Jinbiao $Z$ et al. [23] conducted a test on affixing CFRP cloth to reinforce damaged wooden beams. Among them, the damaged member adopts an idealized design, that is, a notch of $40 \mathrm{~mm}$ width and $25 \mathrm{~mm}$ height is placed in the middle of the tension surface of the member, and the same type of wood block is fixed at the notch with a specific adhesive: CFRP cloth can effectively improve the damaged wood The stiffness, ductility and flexural capacity of the beam can increase the flexural capacity of the damaged wooden beam by $12 \%$ to $65 \%$.

\subsubsection{CFRP material reinforced gluam beams}

Dagher et al [24] and Brunner [25] carried out tests on CFPR cloth reinforced simply supported and glulam beams respectively: the reinforcement members were damaged by the brittle fracture of the tensioned wood; 
the stiffness of the members after reinforcement was increased by $25 \%$ to $37 \%$. The flexural capacity is increased by $22 \%$ to $51 \%$. Micelli et al [26] carried out three cemented wood beam spanning connections (the length of the CFRP ribs of the compression surface was $300,400,500 \mathrm{~mm}$, and the length of the CFRP ribs of the tensioned faces were 800,900 and $1000 \mathrm{~mm}$, respectively). Test: CFR and epoxy The flexural capacity of the resin for the inter-connected timber beams is $70 \%$, $74 \%$, and $93 \%$ of the unconnected test specimens respectively. That is, the flexural capacity of the CFRP tendons is basically restored under the premise of ensuring the anchor length of the CFRP tendons. Zhuo J et al [27] studied the effect of different bonding methods and layers of CFRP cloth on timber beams. Xiaojun Y and Youfu $\mathrm{S}$ [28] conducted a preliminary study on the flexural properties of CFRP and CFRP-reinforced glulam with larch as the substrate. The test shows that the CFRP plate is pre-bent in the sub-surface of the glulam wood. The flexural strength and flexural modulus of the wood are significantly improved, and the appearance, connection and surface processing are not affected. Thheri, Nagaraj et al. [29] used CFRP, GFRP, metal plates, bamboo fibers and other reinforced glulam beams to compare the strength and stiffness of reinforced timber beams with different materials. Haibei $X$, Yingyang L et al. [30] conducted an experiment on the anti-side properties of beam-column glulam structures reinforced with carbon fiber sheets. Studies have shown that the carbon fiber cloth reinforcement method can effectively inhibit crack development, restore the strength, stiffness, ductility and other lateral strength properties of damaged structures, and improve energy consumption. Peng S, Youfu S et al. studied the hollowglued beam-column system, the test carried out the lateral stress-resistance performance of the beam-column simple frame system and the herringbone reinforcement system [31], but the reinforcement and maintenance after the damage have not been considered. The author believes that the carbon fiber cloth reinforcement research can be carried out in combination with the above documents, which has certain research value and practical engineering significance.

\subsection{Further research is needed in the following areas}

\subsubsection{Durability of the adhesive}

Relevant researches have shown that GFRP has a good effect in repairing reinforced timber beams, and its bearing capacity, stiffness and ductility are improved. However, it relies on the bonding of adhesives, has durability problems, and affects the components of appearance effect.

\subsubsection{Reinforcement of hollow glulam components}

Hollow-glued timber structure beam-column system and node CFRP reinforcement technology. The hollow timber beam column has been proved to have excellent mechanical properties, considering its practical application and possible problems in actual engineering in the future, it is necessary to study the effect and durability of CFRP reinforcement technology.

\subsubsection{The establishment and improvement of relevant norms}

Relevant specifications and basis need to be gradually established. The CFRP material reinforced timber structure is an emerging reinforcement method, which has many advantages such as easy construction, no influence on the structure's own weight and appearance, and is very worthy of being promoted. However, the current specifications and basis for the reinforcement of glulam structure of CFRP materials are scarce, which is not conducive to the application of the reinforcement method.

\section{Conclusions}

Timber beams play an important role in timber structure construction, especially with the rise of high-rise timber structure buildings, the mechanical properties of the beam strength, stiffness, bearing capacity and other mechanical strengths and joint stress are gradually receiving attention. In addition, the research on timber beams is no longer limited to the timber itself. At the same time, considering the combination of timber, steeltimber composite [32], timber-plastic composite and material reinforcement, the safety of the timber beam in the process of stress is guaranteed. The author believes that the repair and reinforcement technology of timber beams has gradually matured, which also provides technical support for the development of wooden construction, therefore it is believed that the development of timber building industry will have a bright future [33].

\section{References}

1. Yingmin $\mathrm{J}$, The Damage and Reinforcement of Timber Beams in Historical Buildings, Hans Journal of Civil Engineering, 2015, (4) , 151-157

2. Blass, H.J. and Bejtka, I. Reinforcements perpendicular to the grain using self-tapping screws. Proceedings of the World Conference on Timbergineering, 2004, 1001-1006.

3. Zhiyong $\mathrm{C}$ et al. Refined finite element simulation of vertical force performance of Yingxian Mutadou arch. Science and Technology and Engineering, 2012(12):819-824.

4. Qian $Z$ et al. Research on the reinforcement method of ancient building timber structure. Earthquake 
Resistant and Reinforcement Engineering, 2009(31):84-91.

5. Yizi W. Notes on Engineering Practices. China Building Industry Press, Beijing, 1995: 278-281.

6. Marzi T. Nanostructured materials for protection and reinforcement of timber structures: A review and future challenges[J]. Construction and Building Materials, 2015(97): 119-130.

7. Hansen, K.F. Mechanical properties of self-tapping screws and nails in timber. Canadian Journal of Civil Engineering, 2002(29), 725-733.

8. Jonsson, J. Load carrying capacity of curved glulam beams reinforced with self-tapping screws. HolzalsRoh- Und Werkstoff, 2005(63) :342-346.

9. Xiaobin S, Yajie W, Yingmin J. New self-tapping screws to repair the bending resistance of longitudinally-slit wooden beams. Journal of Nanjing University of Technology (Natural Science Edition), 2016, 38( 5) : 45-51.

10. Minjuan $\mathrm{H}$, Yi Z, Chengyong $\mathrm{G}$ et al. Journal of Tongji University (Natural Science Edition).2015(06):845-852.

11. Lei C. Study on mechanical properties of glulam beam. Doctoral thesis of Central South University of Forestry and Technology, Changsha, China, 2017.

12. Deliang $\mathrm{X}$, Weiqing $\mathrm{L}$, Huifeng $\mathrm{Y}$ et al. Experimental study on bearing capacity of woodsteel floor bolt connection[J].2009(01): 87-91,96.

13. Yuhui Y, Wei X, Nan G. Bending resistance of steel reinforced wood beams.Journal of Jilin University.2017 (02) ,468-477.

14. Feibin W, Xiaolin Y, Zeli Q et al.Study on the flexural behavior of GFRP-reinforced reinforced wood beams. China Forest Products Industry,2017(11):18-23.

15. Caisong L, Yuhui H. Review on the reinforcement and maintenance methods of ancient building timber structures . Fujian Architecture, 2005, 5 (6): 196.

16. Lam F.eholff M, Closen M. Moment-resisting bolted timber connections. Structures and Buildings, 2010, 163.

17. Plevris N, Triantafillon T. FRP-reinforced timber as structural material . Journal of Materials in Civil Enginnering. 1992, 4(3): 300-317.

18. Dazhao Z. Study on the performance of CFRP sheet for reinforcing wooden column beam . Shanghai, China: Tongji University, 2003.

19. Johns K, Lecroix S. Composite Reinforcement of Timber in Bending . Canadian Journal of Civil Engineering. 2000, 27(1): 899-906 .

20. Ganga Rao H, Sonti S, Superfesky M. Static Response of Timber Crossties Reinforced with Composite Fabrics. International Society of the Advancement of Materials and Process Engineering Symposium and Exhibition. 1996, 15(3): 12911303.
21. Jianxun Ma, Ping H, Xiangqi J. Experimental study on axial compression performance of wood fiber reinforced timber columns. Industrial Construction. 2005, 35(8): 40-44 .

22. Qingfeng X, Lei Z, Xiangmin L, et al. Flexural Behavior of Timber Beams with Knots Strengthened with CFRP[C]. Proceedings of FRP RCS-8, Greece, 2007 .

23. Jinbiao Z, Baisheng W, Jianbo W. Experimental study on reinforced wooden beams strengthened with carbon fiber sheets. Industrial Construction, 2005, 35(10): 86-89 .

24. Dagher H J, Kinball T E, Shaler S M, et al. Effect of FRP Reinforcement on low Grade Eastern Hemlock Glulams[C]. Proceedings of 1996 National Conference on Timber Transportation Structures. Madison: 1996.

25. Brunner M, Schnueriger M. Timber Beams Strengthened by Attaching Prestressed Carbon FRP Laminates with a Gradiented Anchoring Device.Proceedings of the International Symposium on Bond Behavior of FRP in Structures (RRF 2005), 2005 International Institute for FRP in Constructions. 2005: 465-471 .

26. Micelli F, Scialpi V, Tegola A. Flexural Reinforcement of Glulam Timber Beams and Joints with Carbon Fiber-Reinforced Polymer Rods. Journal of Composites for Construction. 2005, 9(4): 337-347.

27. Zhuo J. Research on the performance of CFRPreinforced wooden beams [D]. Shanghai, China: Shanghai Jiaotong University, 2009.

28. Xiaojun Y, Youfu S. Study on Bending Behavior of Carbon Fiber Reinforced Glulam. Wood Processing Machinery, 2009(10): 17-19, 22.

29. Thheri F. Nagaraj M.Cheraghi N.FRP-reinforced glulaminnated columns.FRP International,2005.2(3):10.

30. Haibei X, Yingyang L et al. Anti-side performance test of beam-column glulam structure reinforced with carbon fiber cloth[J]. Journal of Tongji University: Natural Science Edition, 2015, 43(10): 1463-1470.

31. Peng S, Youfu S,Dingguo Z et al. Experimental study of the bending performance of hollow glulam beams[J].Timber and Fiber Science,2018,50(01): 3-19.

32. Ying Gao, Yaqin Qiu, Yuting Zhao et al.A prestressed steel-wood composite beam, China, 201720264334.9 .

33. Haiqing R, Zehui J,Benhua $F$ et al. Future development path of modern wood frame housing in China, China Wood Industry,2006,(02):45-47. 